\title{
Studi Komparatif Kriteria Amil Zakat, Hak dan Kewajibannya Pada Lembaga Amil Zakat Nasional (LAZNAS) Di Indonesia
}

\author{
Rahmad Hakim \\ Universitas Muhammadiyah Malang \\ rahmadhakim@umm.ac.id
}

\begin{abstract}
: This study attempt to conduct an in-depth analysis related to the criteria of Amil zakat, along with their rights and obligations in the context of Islamic history and in this contemporary era, especially in LAZISMU Malang City and LAZNAS Nurul Hayat Malang Branch. This research is descriptive qualitative with data collection methods using documentation and interview techniques. Data analysis in this study uses content analysis techniques. The result of the study is that there are differences between Amil zakat criteria and Amil zakat obligations in the past and present, this can be seen in the criteria of Amil zakat in the past including; freeman (not slaves), amanah, trustworthy, restraint, inclined towards goodness, always giving advice. While today, among them are: having the will, accepting guidance, not smoking (for men), understanding Islam, be able to read the Qur'an. On the other hand, Amil zakat in our era depends on the status of the Amil zakat staff concerned, whether the Amil zakat is full-timer or partimer. However, basically, there are similarities between the rights of Amil zakat the past and the presentday, such as the right of Amil which depends on the proportion of Amil's performance or one-eighth (12.5\%) of the collected zakat funds
\end{abstract}

Keywords : : zakah manager; zakah management; history of zakah

\section{Latar Belakang}

Zakat merupakan salah satu rukun Islam (Owoyemi \& Cusairi, 2016). Selain itu, zakat merupakan salah satu instrument dalam pemerataan kesejahteraan dan ekonomi ummat (Kasri, 2016). Dalam sejarah peradaban Islam, zakat merupakan sumber pemasukan Negara tertua setelah pajak. Zakat memiliki arti: suci, bertambah, dan berkembang (Qardhawi, 1996). Ia mensucikan harta orang-orang yang memiliki harta (muzakki) sekaligus mengembangkan harta golongan miskin (mustahik), yaitu: golongan fakir, miskin, ibnu sabīl, ghārim, Amil, fi sabīlillah, riqāb dan muallaf. Sebagaimana firman Allah Swt yang artinya, "Sesungguhnya zakat-zakat itu, hanyalah untuk orang-orang fakir, orang-orang miskin, pengurus-pengurus zakat, Para mu'allaf yang dibujuk hatinya, untuk (memerdekakan) budak, orang-orang yang berhutang, untuk jalan Allah dan untuk mereka yang sedang dalam perjalanan, sebagai suatu ketetapan yang diwajibkan Allah, dan Allah Maha mengetahui lagi Maha Bijaksana" (QS. At-Taubah[5]: 60). Senada dengan ayat di atas, Rasulullah bersabda ketika mengutus sahabat Mu'adz ni Jabal ke Yaman, beliau berwasiat bahwa: "Beritahukan kepada mereka, bahwa Allah mewajibkan mereka untuk (mengambil, pen.) sedekah dari harta mereka, yang diambil dari orang-orang kaya dan disalurkan untuk orang-orang fakir. Jika mereka menta'atimu, maka hati-hatilah engkau dengan harta berharga mereka dan takutlah dengan doa orang yang terdzalimi, karena tidak ada penghalang antara Allah dengannya" (HR. Muslim).

Selain itu, zakat merupakan instrumen pemerataan ekonomi yang unik. Sebab ia bersifat religious-politis, dimana secara garis besar penerapan zakat diatur oleh Agama dan 
Negara (Suharto, 2004). Keunikan lain dari zakat adalah satu-satunya ibadah yang secara eksplisit dikemukakan dalam Al-Quran yang memiliki petugasnya (Hafidhuddin, 2011). Dengan Bahasa lain, zakat merupakan ibadah mahdah yang secara spesifik dijelaskan melalui al-Qur'an dan Sunnah Rasulullah. Akan tetapi, disisi lain, zakat memiliki dimensi politis atau ghairu mahdah; yang dapat berubah seiring berubahnya waktu dan tempat. Sebagaimana dinyatakan oleh Abu "Ubaid dalam al-Amwal, "lā yunkiru taghayyur al-hukm bi taghayyuri al-azminah" -tidak menutup kemungkinan adanya perubahan hukum, seiring perubahan waktu dan tempat ('Ubaid, 2000). Peran 'Amil merupakan salah satu faktor keberhasilan dalam pemerataan pendapat dalam masyarakat. Semakin tinggi kepercayaan masyarakat kepada Amil, semakin besar pendapatan yang diperoleh oleh lembaga Amil zakat (Siregar, 2015); (Hakim, 2017). Menurut Adnan (2015), di antara banyak faktor yang berkontribusi pada pengembangan zakat adalah keberadaan dan peran Amil zakat. Tanpa Amil pengembangan Zakat akan sia-sia. Namun, tidak banyak perhatian yang diberikan kepada mereka. Padahal menurut Huda, \& Sawarjuwono (2013), diantara problem zakat di Indonesia ialah keterbatasan tenaga Amil zakat yang profesional. Di sisi lain, lembaga zakat memiliki tanggung jawab sangat besar yaitu memastikan pengumpulan dan distribusi zakat kepada yang membutuhkan dengan efisien dan efektif. Jika lembaga gagal berfungsi dengan baik, maka sistem zakat tidak akan berhasil dilaksanakan. Lembaga-lembaga zakat perlu menunjukkan nilai-nilai Islam yang tinggi, seperti kepercayaan dan keadilan dalam pengelolaan zakat (Possumah, 2016).

Maka dari itu, penelitian ini bertujuan untuk membahas secara mendalam terkait kriteria Amil, hak dan kewajibannya pada Lembaga Amil Zakat, Infak dan Shodaqoh Muhammadiyah (LAZISMU) dan Lembaga Amil Zakat Nasional (LAZNAS) Nurul Hayat Cabang Malang.

\section{Teori dan Metode}

\subsection{Amil Zakat}

Menurut Ibnu Katsir, Amil zakat adalah mereka yang mengatur dan berusaha dalam mengelola zakat, mereka tidak diperbolehkan bagi kerabat dekat Rasulullah Saw (Katsir, 2000); (Hakim, 2017). Menurut at-Thabari (2001), Amil zakat adalah orang yang mengusahakan untuk mengambil zakat dari para muzakki, dan mendistribusikannya kepada golongan mustahik, bagiannya sesuai dengan apa yang diusahakannya, baik mereka dalam kondisi kaya atau miskin (Firmansah, 2015). Pendapat ini dikemukakan oleh Az-Zuhriy, Qatadah, Ibnu Zaydin. Menurut al-Andalusi (1993), Az-Zamakshsyari (1998), al-Mahalli dan as-Suyuthi (n.d.), 'Asyur (1984), az-Zuhali (1996), ad-Dimasyqi (1998), Amil adalah seseorang yang mewakili pemerintah dalam usaha untuk mengumpulkan dan mendistribusikan kepada yang berhak, dan petugas Amil terbagi menjadi dua; bagian pengumpulan dan pembagian (Rahayu, 2015); (Aibak, 2016).

Dalam tafsir fi dzilalil Qur'an, Quthb (2003) menjelaskan bahwa petugas zakat adalah orang-orang yang melaksanakan tugas untuk memungut dan mengatur dana zakat (Hakim, 2018). Sedangkan Shihab (2002) menambahkan, bahwa bahasa para pakar hukum menyangkut kata [al- 'Amilina 'alaiha'] dalam (QS. At-taubah[9]: 60) menjelaskan bahwa pengelolanya beragam. Hanya saja, yang pasti bahwa mereka adalah yang melalukan pengelolaan terhadap pengelolaan zakat, baik mengumpulkan, menentukan siapa yang berhak, mencari mereka (orang yang berhak), membagi dan mengantarkan kepada mereka.

Huruf ('ala) setidaknya memiliki beberapa arti, yaitu: pertama, untuk membatasi, artinya bekerja, berusaha, dan mengabdi dan orang-orang yang berusaha guna menghidupkan untuk mengumpulkan zakat harta bergerak (Toriquddin, 2015). Kedua, 
penempatan huruf ('ala) ditempat ini untuk mengokohkan bahwasanya para Amil bekerja keras untuknya, karena usaha dalam kegiatan zakat ini memiliki berbagai macam rintangan dan usaha yang gigih, dan semoga usaha ini dimasudkan untuk dua hal: (a) pekerjaan mereka untuk zakat, (b) karena keterpanggilan jiwa. Ketiga, penempatan kata ('ala) disini berfungsi sebagai pengganti secara tidak langsung (wakil), sebagaimana dinyatakan: dia adalah Amil atas kota Masidah, atau Amil (wakil) Nabi, khlifah, atas zakat atau bekerja tetap untuk Amil zakat ('Asyur, 1984).

Kata ['alaiha] juga memiliki kesan bahwa para pengelola itu melakukan kegiatan mereka dengan sungguh-sungguh dan mengakibatkan keletihan (Rosadi, 2017); (Nopiardo, 2017). Hal ini disebabkan kata ['ala'] mengadung makna pengusaan dan kemantapan akan sesuatu. Penggunaan rangkaian kedua kata itu untuk menunjukkan para pengelola, memberi kesan bahwa mereka berhak memperoleh bagian dari zakat karena dua hal (Hakim, 2020): (1) karena upaya mereka yang berat, (2) karena upaya tersebut mencakup kepentingan sedekah.

Para pengelola zakat seharusnya diangkat oleh pemerintah; dan ketika itu mereka dinilai mewakili penerima zakat (Varlitya, 2017); (Wahyuniati \& Hamid, 2017). Jika mereka tidak diangkat langsung oleh pemerintah dan langsung menerimanya dari kewajiban zakat (muzakki) yang mengangkatnya agar membagikan kepada yang berhak, maka ini mereka berarti menjadi wakil-wakil pemberi zakat (muzakki). Masalahnya adalah, ketika terjadi kehilangan zakat, maka pemberi zakat masih harus mengeluarkan zakat kepada yang berhak menerimanya. Ini berbeda dengan jika yang menghilangkannya adalah pengelola yang ditunjuk oleh pemerintah. Ketika itu yang menyerahkan zakatnya dinilai telah mengeluarkannya. Sebab ia telah menyerahkan zakat kepada yang mewakili pihak penerima yang berhak (Shihab, 2002). Dan hak Amil sebagaimana pendapat Imam Syafi'i adalah seperdelapan melihat jumlah golongan yang berhak adalah delapan (Ridwan, 2016); (Anwar, Aji \& Tanjung, 2019). Sedangkan Imam Malik berpendapat bahwa bagian Amil zakat bergantung kinerja mereka (Hafidhuddin, 2002); (Setiadi, \& Hambali, 2016); (Zahra, Harto \& Ash (2016); (Syafuri \& Anggraeni, 2019). Sedangkan pendapat yang lebih baik adalah bukan dari dana zakat yang terkumpul, akan tetapi dari kas Negara.

Hamka menambahkan, bahwa jika pemerintah berkomitmen penuh terhadap agama, maka zakat dipungut oleh Negara. Negara menentukan pengurus atau pegawai yang akan memungut zakat. Si pengurus atau pegawai berhak pula mendapatkan bagian, akan tetapi perlu maklum bahwa zakat yang dikumpulkan harus terlebih dahulu diserahkan kepada Negara semua, agar tidak mengambil sesuka hatinya. Jika si pemungut zakat menyembunyikan sebagian harta yang dipungutnya untuk kepentingan sendiri, dan tidak dilaporkannya, perbuatan itu dinamakan ghulul atau korupsi. Termasuk dosa besar, sama dengan mecuri (Hamka, 1993).

dalam suatu negeri yang pemungutan zakat dikerjakan oleh ummat Islam sendiri, karena kesadaran agama mereka, mereka boleh mengadakan panitia (komiti) untuk memungut dan mengumpulkan dengan persetujuan bersama, anggota-anggota panitian berhak mendapatkan bagian dari zakat (Hamka,1993). Disebabkan beratnya tanggungjawab dan pekerjaan, atau usahanya yang lain terhenti karena mengurus zakat (Nasrudin, 2017).

\section{Amil Zakat: Kriteria dan Kewajibannya}

Kriteria Amil zakat dalam diskursus fikih , menurut Abu Yusuf (1985); (Susilowati \& Setyorini, 2018): amanah (aminin), terpercaya (tsiqatin), menahan diri ('afifin), cenderung kepada kebaikan (shalah), senantiasa memberi nasehat (nasihin), mempercayai anda (pemerintah) dan rakyatnya (ma'munin 'alaika wa 'ala ra'iyyatika). Sedangkan menurut alMawardi (1960) kriteria yang harus dimiliki oleh petugas zakat adalah: merdeka (bukan 
budak), Muslim, Adil, mengetahui hukum-hukum zakat jika ia pejabat menteri tafwidi (koordinator). Jika ia menjabat sebagai menteri tanfidz (pelaksana) yang diangkat oleh Pemerintah untuk menarik zakat tertentu, maka dibenarkan kalau ia tidak mempunyai pengetahuan tentang hukum-hukum zakat sebab hanya mengikuti arahan (taqlid) sesuai dengan standar operasional yang telah ditetapkan (SOP).

Pemerintah dapat menentukan petugas Amil zakat (tanfid) melalui tiga skenario sebagai berikut (al-Mawardi, 1960):

a) Pemerintah mengangkatnya sebagai petugas zakat dengan dengan tugas mengambil zakat dari orang-orang yang terkena wajib zakat (muzakki) sekaligus mendistibusikannya kepada penerimanya. Jadi pemerintah diperbolehkan untuk menggabungkan dua tugas tersebut kepada petugas zakat

b) Pemerintah mengangkat petugas zakat dengan tugas pemungutan zakat saja tanpa mendistribusikan kepada para penerimanya. Jadi petugas tersebut hanya bertugas memungut zakat an sich. Kecuali jika kemudian hari, ia diangkat menjadi petugas zakat dengan tugas mempercepat ( $t a{ }^{\prime} j i l$ ) pendistibusiannya kepada orang-orang tertentu.

c) Pengangkatan petugas zakat bersifat umum. Yaitu dengan tidak memerintahkan untuk menditribusikan zakat dan juga tidak melarangnya. Pengangkatan umum seperti ini harus ditafsirkan mencakup mengambil zakat dan mendistribusikannya. Masing-masing dari dua permasalah tersebut mempunyai hukum dan keahlian tersendiri.

Qardhawi menyatakan bahwa seseorang yang ditunjuk sebagai Amil zakat atau pengelola harus memiliki beberapa persyaratan sebagai berikut (Qardhawi, 1996); (Atabik, 2016); (Zen, 2017):

a) Beragama Islam. Syarat ini mempertimbangkan bahwa zakat merupakan salah satu dari rukun Islam, dan urusan penting kaum Muslimin. Olehnya tidak dibenarkan jika bukan muslim yang menjadi Amil zakat.

b) Dewasa (mukallaf). Pengelolaan zakat memerlukan kemampuan untuk berfikir, dan tanggungjawab yang harus dipikul disebabkan mengurus urusan ummat muslimin

c) Amanah (jujur). Menurut beberapa ahli tafsir, dimensi amanah meliputi iman kepada Allah, sesama dan diri sendiri (al-Andalusi, 1993). Dalam konteks kontemporer, amanah disini dapat juga dipadankan dengan istilah transaparansi, akuntabilitas dalam penyampaian laporan secara berkala. Amanah ini sangat penting dalam kaitanya dengan sebuah pekerjaan yang mengurusi kepentingan umum (maslahatul ummah) sebagimana dinyatakan dalam (QS. Yusuf[12]: 55), yang artinya: "Berkata Yusuf: "Jadikanlah aku bendaharawan negara (Mesir); Sesungguhnya aku adalah orang yang pandai menjaga, lagi berpengetahuan”.

d) Kompeten dalam hukum zakat. Untuk menjadi petugas zakat tidak hanya memungut dan menyalurkan saja. Namun masih banyak pekerjaan yang harus dilakukan. Diantaranya adalah; melakukan penghitungan besara zakat yang dikenakan kepada wajib zakat, sosialisasi segala sesuatu yang berkaitan dengan zakat kepada masyarakat, inventarisir daftar para wajib zakat sekaligus mustahik, dan inventarisir kebutuhan dari para penerima zakat begantung golongannya (fakir, miskin, gharim, riqab, fi sabilillah, ibnu sabil, Amil dan muallaf). Kecakapan ini harus dimiliki guna meminimalisir kesalahan dalam menetapkan hukum dan perlakukan (treatment) dalam menentukan nominal zakat

e) Memiliki kemampuan untuk menjalankan tugas Amil zakat. Kemampuan disini bisa dilihat dari beberapa perpektif, misalnya: mampu secara waktu, keahlian, fisik, fikiran dan tanggungjawab. 
f) Sarat yang terakhir adalah komitmen Amil dalam menjalankan tugasnya. Amil zakat yang baik adalah yang bekerja secara full-time dalam menjalankan tugasnya, bukan sambilan (part-time) dan asal-asalan. Asal-salan dan sambilan menyebabkan Amil zakat bersifat pasif hanya menunggu wajib zakat memberikan dananya kepada mereka. Model seperti ini sebagian hanya ada ketika bulan Ramadhan saja. Amil yang seperti ini harus diganti dengan yang sungguh-sungguh dan punya passion sebagai petugas Amil zakat sehingga dapat meningkatkan kepercayaan masyarakat (Hafiduddin, 2008).

Di sisi lain, beberapa kewajiban para petugas zakat dalam sejarah Islam adalah sebagai berikut (Yusuf, 1985) ('Ubaid, 2000); (al-Mawardi, 1960); (al-Bantani, 2004); (Hakim, 2017): pertama, berlaku jujur (bi akhdi al-haq wa i'tha'i man wajaba lahu). Kedua, mengikuti sunnah Rasulullah dan khalifah setelahnya (al- 'amalu bi ma sannahu Rasullah tsumma al-khulafa' min ba'dihi). Ketiga, tidak menggabung (objek zakat) yang seharusnya terpisah, dan vica versa (la yajma' bayna mutafariqa wa la yufriq bayna mujtama'). Keempat, cermat dalam penghitungan (an-yatakhayyar bil washati). Kelima, tidak membawa harta zakat keluar wilayahnya (la yambaghiy li sahibi as-sadaqah an yajliba alghanama min biladin ila biladin). Keenam, tidak memungut zakat hingga sampai haul (la tu'khadu as-shadaqatu min al-ibili wa al-baqari wa al-ghanami hatta yahula 'alaiha alhaul).

Ketujuh, tidak mencampur antara harta pajak dan harta zakat (la yambaghiy an yujma' mal al-kharaj il mal as-shadaqah wa al-'usyr). Kedelapan, harus mendoakan muzakki agar termotivasi untuk bersegera membayar zakat. Kesembilan, jika terdapat wajib pajak menyembunyikan hartanya, padahal petugas zakat berlaku adil dalam tugasnya, maka petugas zakat berhak mengambilnya ketika melihat hal itu. Dan melakukan penelitian terkait motif daripada penyembunyian tersebut.

Jika muzakki menyembunyikan karena ingin mengelola dan mengeluarkan sendiri, petugas zakat tidak boleh menjatuhkan ta'zir (sanksi disiplin) kepadanya. Namun jika disembunyikan karena faktor untuk meringankan kewajiban zakat, maka petugas zakat boleh menjatuhkan ta'zir kepadanya. Kesepuluh, tidak diperkenankan bagi Amil untuk menerima risywah dan hadiah. Sebagaimana sabda Rasulullah Saw. "hadaya al- 'ummal ghulul" hadiah bagi para Amil (zakat), adalah sesuatu yang berlebihan (pencurian)

\section{Hak dan Bagian Amil Zakat}

Hak Amil atas zakat merupakan pengecualian (istisna'), jika pemberian atas golongan penerima zakat adalah dikarenakan mereka tidak mampu (innama as-shadaqatu lil fuqara wal masakin), maka bagi Amil hal tersebut tidak relevan (Hakim, 2018). Terdapat dua alasan pemberian hak bagi Amil zakat: pertama, riwayat Ibnu al-Qasim yang membolehkan mujahid dan Amil zakat mendapatkan hak atas zakat. Kedua, terdapat hadist yang menyatakan bahwa zakat diperbolehkan bagi lima golongan kaya, salah satunya adalah bagi Amil zakat. Hal ini disebabkan, Amil mendapatkan bagian atas dasar manfaat, sedangkan golongan yang lain atas dasar kebutuhan (Rusyd, n.d.); (Al Arif, \& Rianto, 2013), sebagaimana dinyatakan dalam sabda Rasulullah Saw,

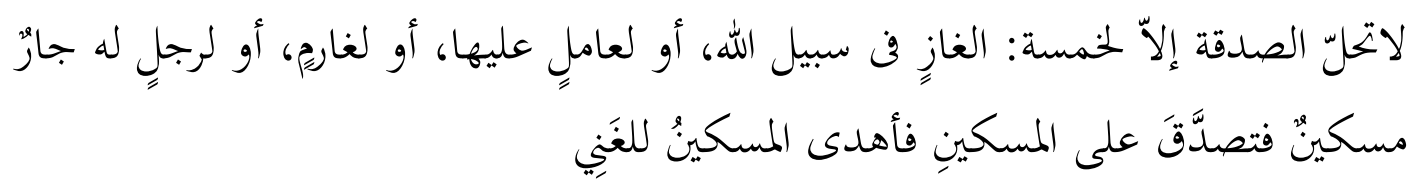


Rasulullah Saw Bersabda, "sedekah tidak diperbolehkan kecuali dalam lima hal: bagi yang berperang di jalan Allah, Amil zakat, orang kaya yang bangkrut, atau seseorang yang kaya menghadiahkan tetangganya yang miskin, namun si miskin memberikannya sebagai hadiah kepada si kaya (HR. Muslim)

Sementara dalam bagian Amil Zakat, para ulama' berbeda pendapat dalam porsi bagian para Amil Zakat (Hanif, 2018); (Syafuri, \& Anggraeni, 2019). sebagian menyatakan bahwa bagian mereka adalah seperdelapan (tsumun), diantara mereka yang berpendapat ini adalah Ibnu Waqi', Khumaid Ibn Abdurrahman, Hasan Bin Shalih, Jubair, Dihak, Muslim bin Khalid, Ibnu Abi Najih, Mujahid, Mujahid, Dihak, dan as-Syafi'i (at-Thabari, 2001). Sebagian lain menyatakan bahwa bagian Amil zakat bergantung kepada pekerjaannya atau upah yang sepadan dengan pekerjaannya (ajrin mitslihi) (at-Thabari, 2001), dalam konteks modern dikenal dengan UMR (upah minimum regional). Diantara mereka yang berpendapat ini ialah khalifah 'Umar, Hasan, dan Abu Ja'far, Imam Malik. Dan menurut Malik diriwayatkan oleh Abi Uwais dan Daud bin Sa'id, diberikan dari baitul mal (al-Andalusi, 1993)

Perbedaan pendapat juga terjadi pada Amil zakat jika ia seorang yang kaya, bolehkah Amil zakat mengambil bagiannya?. Pendapat pertama menyatakan bahwa Amil zakat tidak boleh mengambil bagian (atas dasar maslahat) kecuali jika ada keperluan yang mendesak. Sebagian lain berpendapat bahwa boleh mengambil bagian, sebab bagian Amil merupakan upah (ujrah) atas pekerjaan yang telah dilakukan. Sebagian lagi menyatakan Amil boleh mengambil tetapi hanya seperdelapan atau $12.5 \%$, pendapat ini adalah menurut mereka yang berpendapat bahwa harta zakat harus dibagikan secara rata kepada mustahik zakat yang delapan. Namun kebanyakan ulaman (jumhur) berpendapat bahwa bagian Amil berdasarkan proporsi tugasnya, baik sebagai pengumpul maupun pembagi zakat (ar-Razi, 1981).

Menurut al-Mawardi (1960), Amil zakat terbagi kepada dua golongan: pertama, Amil yang bertugas sebagai pemungut zakat. Kedua, Amil yang bertugas untuk mendistibusikan, mengklasifikasi zakat yang tediri dari: ketua, bendahara, humas (mubasyir) dan anggota. Allah Swt. menentukan bagian mereka dari harta zakat, agar tidak ada lagi selain zakat yang diambil, sebagaimana dinyatakan dalam sabda Rasulullah Saw, "laisa $f i$ al-mal siwa az-zakat' -tiada kewajiban lain selain (kewajiban) zakat (HR. Ibnu Majah). Bagian mereka besarnya sesuai dengan pekerjaan mereka (ujur amtsalihim). Jika bagian mereka berlebih, maka diberikan kepada yang lebih membutuhkan (fakir dan miskin). Jika kurang, kekurangnnya diambil dari baitul mal menurut salah satu pendapat. Sedangkan menurut pendapat yang lain, diambilkan dari uang zakat (al-Mawardi, 1960).

Amil zakat dewasa ini terbagi menjadi tiga, yaitu: Amil zakat full-timer, part-timer dan musiman. Menurut Hafiduddin, (2008) porsi seperdelapan atau 12,5\% adalah lebih tepat diberikan kepada Amil dalam jenis yang pertama. Dengan catatan petugas Amil tersebut memang melakukan tugas-tugas dengan sebaik-baiknya. Namun jika Amil zakat dikerjakan secara musiman atau sambilan (aktif hanya di bulan Ramadhan saja), maka seyogianya para Amil jenis ini hanya mendapatkan bagian sekedarnya saja. Bagainnya sebatas upah untuk kinerja administrasi, konsumsi dan transportasi yang lakukan. Misalnya sebesar (5\%) lima persen saja. Mas'udi (2010) menambahkan, bahwa termasuk hak para Amil juga meliputi: (1) mendapatkan tempat tinggal dan pelayan. Jika ia tidak memiliki tempat tinggal, hendaklah disewakan rumah untuk tempat tinggalnya selama ia betugas, (2) mencari pelayan dan tempat, dengan menambah upah yang diterimanya.

\subsection{Metode penelitian}

Penelitian ini bertujuan untuk mengungkap bagaimana kriteria Amil beserta hak dan kewajibannya pada LAZISMU Kota Malang dan LAZNAS Nurul Hayat Cabang Malang. Jenis penelitian ini adalah penelitian kualitatif-deskriptif. Deskriptif karena karena penelitian 
ini bertujuan untuk melakukan pemecahan masalah yang ada pada masa sekarang, disisi lain penelitian ini berusaha untuk menuturkan, menganalisa, dan mengklasifikasi penyelidikan. Penelitian ini menggunakan pendekatan studi kritis, karena bertujuan untuk melakukan pembandingan terhadap kriteria Amil, hak dan kewajiban serta budaya organisasi di masa lalu dengan yang terjadi saat ini (Nazir, 1998).

Teknik pengumpulan data menggunakan wawancara dan dokumentasi (Raco, 2003). Untuk memudahkan dalam memilih jenis data dalam penggunaan metode dokumenter, penulis melakukan klasifikasi dalam sumber pengumpulan data, yaitu: sumber primer dan sekunder (Nazir, 1998). Sumber primer dalam penelitian ini sumber primer adalah dengan menggunakan karya-karya autentik dari Yahya Ibn Adam, Abu Ubaid al-Qasim dan Abu Yusuf. Sedangkan sumber sekunder dalam penelitian ini adalah penelitian para cendekiawan yang memiliki objek kriteria Amil, hak dan kewajiban serta budaya organisasi.

Dalam rangka mencari penelitian tersebut digunakan instrument on-line dan off-line. Instrument on-line dengan melakukan pencarian menggunakan program google scholar, dan open journal access yang dimiliki oleh universitas. Sedangkan melalui instrumen off-line adalah dengan mendatangi sejumlah perpustakaan guna mencari penelitian atau karya yang berkaitan dengan topik di atas.

Analisis data dalam penelitian ini menggunakan analisis data konten (content data analysis) (Bungin, 2003), yaitu analisis data yang diawali dengan menemukan lambanglambang tertentu; dalam hal ini adalah melakukan inventarisir terhadap teks-teks yang relevan dengan topik penelitian kriteria Amil, hak dan kewajiban serta budaya organisasi. Setelah teks tersebut telah di inventarisir, maka dilakukan klasifikasi data berdasarkan klasifikasi perihal kriteria Amil, hak dan kewajiban serta budaya organisasi. Selanjtunya adalah melakukan prediksi atau analisis terkait data yang telah terklasifikasi tersebut.

\section{Hasil dan Pembahasan}

\subsection{Kriteria Amil Zakat Pada LAZISMU Kota Malang dan LAZNAS Nurul Hayat Cabang Malang}

Kriteria Amil zakat pada Lembaga Amil Zakat, Infak dan Shodaqoh Muhammadiyah (LAZISMU) Kota Malang didasarkan kepada kemauan yang tinggi seseorang dalam mengemban profesi Amil zakat. Selain itu, mereka harus mampu untuk bekerja keras dan bekerja secara tim, saling membantu dengan yang lain serta bekerja dengan keteraturan dan ketertiban (Zakaria Subiantoro, Wawancara, 26, 7, 2017). Hal ini di konfrimasi oleh Bapak Khusnul Bendahara pada LAZISMU Kota Malang, dinyatakan bahwa syarat awal untuk menjadi Amil zakat adalah dia mau bergabung, setelah itu akan dilakukan pembinaan sehingga secara mental mampu dan memiliki kecakapan menjadi Amil zakat (Khusnul, Wawancara, 19, 7, 2017).

Istilah Super Tim sudah di kenal oleh para mustahik zakat LAZISMU Kota Malang dengan adanya testimoni mustahik bernama Sofiyah, seorang janda dua anak, yang menyatakan bahwa semoga LAZISMU super tim dapat dipercaya oleh banyak orang dan donaturnya bertambah. Sehingga dapat mengentaskan kemiskinan, terutama di sekitar Masjid (Buletin Mata Hati, ed. 3 (November), 2016). Pengelolaan zakat pada LAZISMU, didasarkan pada idealisme bahwa lembaga ini merupakan bagian dari Muhammadiyah yang bergfungsi sebagai gerakan amar ma'ruf nahi mungkar dan juga profesi Amil adalah 
tertera dalam al-Qur'an. Maka profesi Amil harus dijalankan secara profesional (Zakaria Subiantoro, Wawancara, 26, 7, 2017).

Sementara itu, pada lembaga Nurul Hayat para Amil zakat di istilahkan sebagai santri. Sebab mereka tidak hanya bekerja, akan tetapi juga mendapatkan materi keagamaan yang didapatkan dari kajian yang dilakukan di lingkungan kerja. Sebagaimana dinyatakan bahwa, Upaya konsolidasi dan penyamaan persepsi di antara pada Amil zakat, melihat latar belakang pendidikan mereka adalah heterogen, yang berasal dari berbagai macam pendidikan dan jurusan. Harapannya adalah guna meningkatkan kinerja dari waktu ke waktu (Indra, Wawancara, 26, 7, 2017).

Kriteria Amil di Lembaga Amil Zakat Nasional (LAZNAS) Nurul Hayat Cabang Malang yaitu; tidak merokok (bagi laki-laki), dan memiliki kecakapan dalam memahami agama Islam, serta mampu membaca al-Qur'an. Kriteria ini dimaksudkan untuk memperoleh input yang baik dalam sumber daya manusia. Pengetahuan tentang Islam yang dimaksud adalah perihal dasar-dasar agama seperti rukun Iman, rukun Islam. Selanjutnya adalah tes tulis perihal pengetahuan umum tentang zakat dan infak (Indra, Wawancara, 26, 7, 2017).

Guna meningkatkan religiusitas para Amil zakat, terdapat sebuah kewajiban bagi mereka untuk selalu menjalankan sunnah harian yang telah ter-sistem; sunnah harian ini menjadi salah satu penilaian kinerja para Amil zakat. Jika nilainya kurang maka akan mendapat punishment, sebaliknya akan diberikan reward berupa insentif dalam bentuk materi (Indra, Wawancara, 26, 7, 2017). Untuk meningkatkan kapabilitas Amil zakat dilakukan pelatihan-pelatihan oleh LAZIS Nurul Hayat berdasarkan tupoksi dalam pekerjaan. Pelatihan tersebut meliputi service excellent, dan juga perubahan programprogram yang ada di lembaga. sebagaimana dinyatakan oleh (Farid, Wawancara, 18, 9, 2017).

Tabel 1: Perbandingan Kriteria Amil Zakat, Hak dan Kewajibannya dalam Teori dan Praktik

\begin{tabular}{|c|c|c|c|c|}
\hline \multirow{2}{*}{ No. } & \multicolumn{2}{|c|}{$\begin{array}{c}\text { Kriteria Amil Zakat, } \\
\text { Hak dan Kewajibannya dalam Teori }\end{array}$} & \multicolumn{2}{|c|}{$\begin{array}{c}\text { Kriteria Amil Zakat, } \\
\text { Hak dan Kewajibannya } \\
\text { dalam Praktik }\end{array}$} \\
\hline & Uraian & Dalam Sejarah Islam & $\begin{array}{l}\text { LAZISMU } \\
\text { Kota Malang }\end{array}$ & $\begin{array}{c}\text { LAZNAS } \\
\text { Nurul Hayat } \\
\text { Cabang Malang }\end{array}$ \\
\hline 1 & $\begin{array}{l}\text { Kriteria } \\
\text { Amil } \\
\text { Zakat }\end{array}$ & 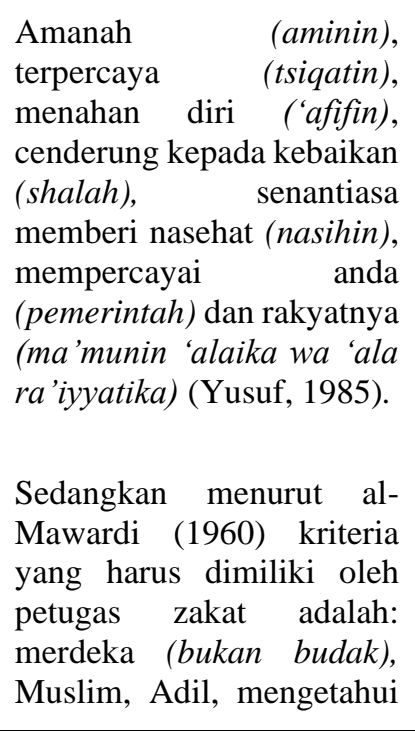 & $\begin{array}{l}\text { Kriteria Amil zakat pada } \\
\text { Lembaga Amil Zakat, Infak } \\
\text { dan Shodaqoh } \\
\text { Muhammadiyah } \\
\text { (LAZISMU) Kota Malang } \\
\text { didasarkan kepada kemauan } \\
\text { yang tinggi seseorang } \\
\text { dalam mengemban profesi } \\
\text { Amil zakat. Selain itu, } \\
\text { mereka harus mampu untuk } \\
\text { bekerja keras dan bekerja } \\
\text { secara tim, saling } \\
\text { membantu dengan yang lain } \\
\text { serta bekerja dengan } \\
\text { keteraturan dan ketertiban. } \\
\text { Dengan kata lain, syarat } \\
\text { awal untuk menjadi Amil } \\
\text { zakat adalah dia mau }\end{array}$ & 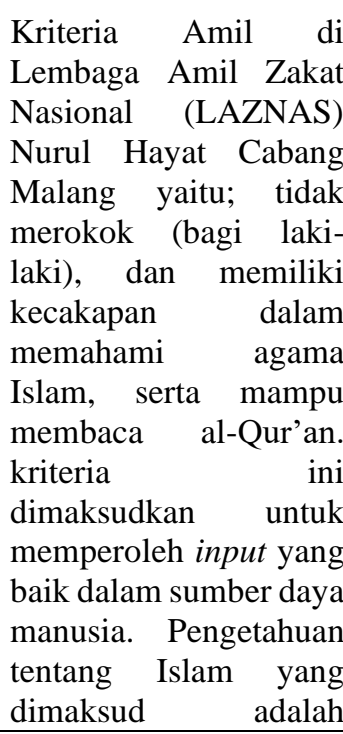 \\
\hline
\end{tabular}




\begin{tabular}{|c|c|c|c|c|}
\hline & & $\begin{array}{l}\text { hukum-hukum zakat jika ia } \\
\text { pejabat menteri tafwidi } \\
\text { (koordinator). Jika ia } \\
\text { menjabat sebagai menteri } \\
\text { tanfidz (pelaksana) yang } \\
\text { diangkat oleh Pemerintah } \\
\text { untuk menarik zakat } \\
\text { tertentu, maka dibenarkan } \\
\text { kalau ia tidak mempunyai } \\
\text { pengetahuan tentang } \\
\text { hukum-hukum zakat sebab } \\
\text { hanya mengikuti arahan } \\
\text { (taqlid) sesuai dengan } \\
\text { standar operasional yang } \\
\text { telah ditetapkan (SOP). }\end{array}$ & $\begin{array}{l}\text { bergabung, setelah itu akan } \\
\text { dilakukan pembinaan } \\
\text { sehingga secara mental } \\
\text { mampu dan memiliki } \\
\text { kecakapan menjadi Amil } \\
\text { zakat. (Zakaria Subiantoro, } \\
\text { Wawancara, 26, 7, 2017). }\end{array}$ & $\begin{array}{l}\text { perihal dasar-dasar } \\
\text { agama seperti rukun } \\
\text { Iman, rukun Islam. } \\
\text { Selanjutnya adalah tes } \\
\text { tulis perihal } \\
\text { pengetahuan umum } \\
\text { tentang zakat dan infak. } \\
\text { (Indra, Wawancara, 26, } \\
\text { 7, 2017). }\end{array}$ \\
\hline 2 & $\begin{array}{l}\text { Kewajiban } \\
\text { Amil } \\
\text { Zakat }\end{array}$ & $\begin{array}{l}\text { (1) berlaku jujur. (2) } \\
\text { mengikuti sunnah } \\
\text { Rasulullah dan khalifah } \\
\text { setelahnya. (3) tidak } \\
\text { menggabung (objek zakat) } \\
\text { yang seharusnya terpisah. } \\
\text { (4) cermat dalam } \\
\text { penghitungan. (5) tidak } \\
\text { membawa harta zakat } \\
\text { keluar wilayahnya. (6) } \\
\text { tidak memungut zakat } \\
\text { hingga sampai haul. (7) } \\
\text { tidak mencampur antara } \\
\text { harta pajak dan harta zakat. } \\
\text { (8) harus mendoakan } \\
\text { muzakki agar termotivasi } \\
\text { untuk bersegera membayar } \\
\text { zakat. (9) jika terdapat } \\
\text { wajib pajak } \\
\text { menyembunyikan hartanya, } \\
\text { padahal petugas zakat } \\
\text { berlaku adil dalam } \\
\text { tugasnya, maka petugas } \\
\text { zakat } \\
\text { mengambilnya } \\
\text { melihat hal itu. Dan } \\
\text { melakukan perhak } \\
\text { terkait motif daripada } \\
\text { penyembunyian tersebut. } \\
\text { (10) tidak diperkenankan } \\
\text { bagi Amil untuk menerima } \\
\text { risywah dan hadiah } \\
\text { (Yusuf, 1985) ('Ubaid, } \\
\text { 2000); (al-Mawardi, 1960) } \\
\text { (al-Bantani, 2004) }\end{array}$ & $\begin{array}{l}\text { Kewajiban Amil zakat di } \\
\text { lembaga ini adalah } \\
\text { kewajiban kinerja lembaga } \\
\text { (sesuai dengan tugas } \\
\text { masing-masing), serta } \\
\text { kewajiban kerja tim yang } \\
\text { harus dijaga. (Zakaria } \\
\text { Subiantoro, Wawancara, } \\
26,7,2017)\end{array}$ & $\begin{array}{l}\text { Kewajiban Amil zakat } \\
\text { di lembaga ini terbagi } \\
\text { menjadi dua, yaitu: } \\
\text { kewajiban invidu dan } \\
\text { kewajiban kinerja } \\
\text { lembaga (sesuai dengan } \\
\text { tugas masing-masing). } \\
\text { (Indra, Wawancara, 26, } \\
\text { 7, 2017). }\end{array}$ \\
\hline
\end{tabular}

\subsection{Bagian Amil Zakat Pada LAZISMU Kota Malang dan LAZNAS Cabang Malang}

Pada LAZISMU Kota Malang, Amil zakat terbagi menjadi tiga golongan, yaitu: Amil tetap yang biasa di sebut dengan koordinator kecamatan (KORCAM), Amil tidak tetap, dan petugas pelaksana di lapangan.

Hak bagi Amil tetap jika tidak mencapai target pengumpulan minimal Rp. 8.000.000 per bulan adalah sebesar Rp. 800 ribu per-bulan dan atau mendapat $10 \%$ dari total pengumpulan zakat. Namun jika Amil mencapai target nominal pengumpulan 8.000.000 
atau lebih per-bulan maka mereka mendapatkan bagian setara dengan upah minimum regional (UMR) Kota Malang (Yuli, Wawancara, 19, 7, 2017).

Selanjutnya, bagian Amil tidak tetap adalah uang transport selama dua bulan pertama, kemudian mereka akan mendapat mendapatkan bagian Amil sebesar $10 \%$ dari total dana zakat yang terkumpul (Zakaria \& Yuli, Wawancara, 19, 7, 2017).

Sementara bagian Amil zakat dilapangan ditentukan 10\% berdasarkan total dari total pengumpulan dana zakat. Pada Amil jenis ini, umumnya adalah mereka yang menjadi penanggungjawab pengumpulan zakat di masjid-masjid dan ranting-ranting Muhammadiyah. Mereka tidak mendapat target dana yang terkumpul selama satu bulan. Hanya saja mereka mendapatkan bagian Amil sebesar $10 \%$ dari total dana zakat yang terkumpul.

Di sisi lain, selaras dengan LAZISMU kota Malang, bagian Amil zakat pada LAZNAS Nurul Hayat Cabang Malang dikategorikan pada tiga jenis, yaitu Amil zakat tetap, Amil kontrak, dan Amil relawan. masing-masing jenis Amil memiliki jenjang dan bagian yang berbeda (Indra, Wawancara, 26, 7, 2017). Bagian Amil tetap adalah insentif yang telah ditetapkan sebagai karyawan tetap pada LAZNAS Nurul Hayat. Hal ini merupakan ciri khas dari LAZNAS Nurul Hayat, bahwa lembaga ini tidak mengambil hak Amil dari dana zakat, akan tetapi insentif Amil zakat berasal dari unit bisnis yang mereka miliki, seperti Aqiqah Nurul Hayat dan Jasa Biro Tour and Travel Umrah Haji.

Tabel 2: Perbandingan Hak Amil Zakat di LAZISMU Kota Malang dan LAZNAS Nurul Hayat Cabang Malang

\begin{tabular}{|c|c|c|c|}
\hline No. & Jenis Amil & LAZISMU Kota Malang & $\begin{array}{c}\text { LAZNAS Nurul Hayat } \\
\text { Cabang Malang }\end{array}$ \\
\hline 1 & Amil Tetap & $\begin{array}{l}\text { Pada LAZISMU Kota Malang, } \\
\text { Amil zakat terbagi menjadi tiga } \\
\text { golongan, yaitu: Amil tetap } \\
\text { yang biasa di sebut dengan } \\
\text { koordinator kecamatan } \\
\text { (KORCAM), Amil tidak tetap, } \\
\text { dan petugas pelaksana di } \\
\text { lapangan. } \\
\text { Hak bagi Amil tetap adalah jika } \\
\text { Amil tetap (KORCAM) tidak } \\
\text { mencapai target nominal yang } \\
\text { telah di tentukan (pengumpulan } \\
\text { minimal } 8 \text { juta per bulan) maka } \\
\text { mereka menerima bagian } \\
\text { pengumpulan dana sebesar Rp. } \\
800 \text { ribu per-bulan, dan } 10 \% \\
\text { dari total pengumpulan zakat. } \\
\text { Namun jika mereka mencapai } \\
\text { target nominal pengumpulan } 8 \\
\text { juta per-bulan, maka mereka } \\
\text { mendapatkan bagian setara } \\
\text { dengan upah minimum regional } \\
\text { (UMR) Kota Malang. }\end{array}$ & $\begin{array}{l}\text { Adapun bagian Amil Pada LAZNAS } \\
\text { Nurul Hayat Cabang Malang dapat } \\
\text { dikategorikan di mulai dari jenjang } \\
\text { Amil zakat tetap, Amil kontrak, } \\
\text { hingga Amil relawan. masing- } \\
\text { masing jenis Amil memiliki jenjang } \\
\text { dan bagian yang berbeda. } \\
\text { Pada Amil zakat tetap mendapat hak } \\
\text { atas kinerja berasal dari penghasilan } \\
\text { sektor profit. Mereka sama seperti } \\
\text { karyawan sebuah perusahaan. }\end{array}$ \\
\hline 2 & $\begin{array}{c}\text { Amil Tidak } \\
\text { Tetap/Kontrak }\end{array}$ & $\begin{array}{l}\text { Sementara, bagi Amil tidak } \\
\text { tetap, mereka mendapatkan hak } \\
\text { uang transport selama dua bulan } \\
\text { pertama, kemudian mereka } \\
\text { akan mendapat mendapatkan }\end{array}$ & $\begin{array}{l}\text { Disebut dengan Amil Zakat kontrak, } \\
\text { mereka mendapat hak atas kinerja } \\
\text { berasal dari penghasilan sektor } \\
\text { profit. }\end{array}$ \\
\hline
\end{tabular}




\begin{tabular}{|c|c|c|c|}
\hline & & $\begin{array}{l}\text { bagian Amil sebesar } 10 \% \text { dari } \\
\text { total dana zakat yang } \\
\text { terkumpul. }\end{array}$ & \\
\hline 3 & Amil Relawan & $\begin{array}{l}\text { Pada Hak Amil zakat } \\
\text { dilapangan, } \\
\text { ditentukan } 10 \% \text { bagiannya } \\
\text { total dari total pengumpulan } \\
\text { dana zakat. Pada Amil jenis ini, } \\
\text { umumnya adalah mereka yang } \\
\text { menjadi penanggungjawab } \\
\text { pengumpulan zakat di masjid- } \\
\text { masjid dan ranting-ranting } \\
\text { Muhammadiyah. }\end{array}$ & $\begin{array}{l}\text { Amil zakat relawan mendapat upah } \\
\text { berdasarkan kinerja harian. }\end{array}$ \\
\hline
\end{tabular}

Selanjutnya, bagian Amil dalam kategori kontrak sama dengan yang telah ditetapkan dengan karyawan tetap, dalam hal bidang pekerjaan juga memiliki kemiripan. Hanya saja mereka statusnya masih menjadi karyawan kontrak. Masa kontak pertama pada lembaga ini adalah selama tiga bulan, selanjutnya kontrak kedua adalah selama enam bulan. Jika pada masa kontrak kedua ini Amil zakat dianggap dapat memenuhi tuntutan lembaga, baik kewajiban individu (sunnah harian) maupun kewajiban target pengumpulan dana zakat akan diangkat menuju ke Amil zakat tetap (Indra, Wawancara, 26, 7, 2017). Namun jika tidak memenuhi target kerja, kontrak kerja tidak akan diperpanjang.

Di sisi lain, hak Amil relawan adalah berdasarkan kinerja perhari yang telah dilakukan. Amil zakat kategori ini umumnya bekerja hanya pada bulan Ramadhan saja guna penyaluran zakat fitrah dan sebagian zakat mal.

\section{Simpulan}

Hasil penelitian menunjukkan bahwa kriteria Amil zakat pada Lembaga Amil Zakat, Infak dan Shodaqoh Muhammadiyah (LAZISMU) Kota Malang dan Lembaga Amil Zakat Nasional (LAZNAS) Nurul Hayat Cabang Malang berbeda dengan kriteria Amil di masa lalu. Dimana kriteria Amil dalam di masa lalu meliputi; amanah (aminin), terpercaya (tsiqatin), menahan diri ('afifin), cenderung kepada kebaikan (shalah), senantiasa memberi nasehat (nasihin), mempercayai anda (pemerintah) dan rakyatnya (ma'munin 'alaika wa 'ala ra'iyyatika). Sementara kriteria Amil zakat di LAZISMU Kota Malang adalah mereka yang memiliki kemauan bergabung terlebih dahulu, setelah itu akan dilakukan pembinaan sehingga secara mental mampu dan memiliki kecakapan menjadi Amil zakat. Di sisi lain, pada LAZNAS Nurul Hayat Cabang Malang kriteria Amil zakat yaitu: tidak merokok (bagi laki-laki), memiliki kecakapan dalam memahami agama Islam, mampu membaca al-Qur'an.

Selanjutnya, kewajiban Amil zakat meliputi: (1) berlaku jujur (bi akhdi al-haq wa i'tha'i man wajaba lahu). (2) mengikuti sunnah Rasulullah dan khalifah setelahnya (al'amalu bi ma sannahu Rasullah tsumma al-khulafa' min ba'dihi). (3) tidak menggabung (objek zakat) yang seharusnya terpisah (la yajma' bayna mutafariqa wa la yufriq bayna mujtama'). (4) cermat dalam penghitungan (an-yatakhayyar bil washati). (5) tidak membawa harta zakat keluar wilayahnya (la yambaghiy li sahibi as-sadaqah an yajliba al-ghanama min biladin ila biladin). (6) tidak memungut zakat hingga sampai haul (la tu'khadu asshadaqatu min al-ibili wa al-baqari wa al-ghanami hatta yahula 'alaiha al-haul). (7) tidak mencampur antara harta pajak dan harta zakat (la yambaghiy an yujma' mal al-kharaj il mal as-shadaqah wa al-'usyr). (8) harus mendoakan muzakki agar termotivasi untuk bersegera membayar zakat. Sementara kewajiban Amil zakat dewasa ini antara lain: (1) kewajiban kinerja individu (amalan Sunnah harian), (2) kewajiban kinerja lembaga (sesuai dengan tugas masing-masing), (3) serta kewajiban kerja tim yang harus dijaga. 
Adapun hak Amil zakat adalah bergantung kepada status dari kepegawaian Amil yang bersangkutan, apakah Amil zakat tersebut bersifat tetap atau tidak. Namun demikian, secara prinsip antara hak Amil zakat di masa lalu dan kini masih terdapat kesamaan, yaitu hak Amil bergantung kepada proporsi kinerja Amil dan atau seperdelapan (12,5\%) dari dana zakat yang terkumpul. 


\section{DAFTAR PUSTAKA}

Abi al-Qasim az-Zamakhsyari. (1998). Tafsir al-Kasyaf(I). Riyadh: Dar 'Abikan.

Abi Hafs Ibn 'Adil ad-Dimasyqi. (1998). al-Lubab fi 'Ulum al-Kitab. ('Adil Ahmad \& 'Ali Muhammad, Ed.) (I). Beirut-Libanon: Darul Kutub al-'Alamiyyah.

Abi Hasan al-Mawardi. (1960). al-Ahkam as-Sulthaniyyah (I). Beirut-Lebanon: Darul Fikr li at-Tab'ah wa an-Nasyr.

Abi Hayyan al-Andalusi. (1993). Tafsir al-Bahr al-Muhith (I). Beirut-Lebanon: : Dar Kutub al-'Alamiyyah.

Abu 'Ubaid al-Qasim. (2000). Kitab al-Amwal (I). Qahirah: Darussalam li at-Tab'ah wa anNasyr.

Abu Yusuf Ya'qub. (1985). Kitab al-Kharaj (I). Beirut-Qahirah: Dar as-Syuruq.

Adnan, M. A. (2015). The Need of Establishment of Professional 'Amil Zakat To Enhance The Future Zakat Development. In International Conference on Tourism Development, Conference on Accounting and Finance (pp. 1-10). Yogyakarta: Universitas Muhammadiyah Yogyakarta.

Aibak, K. (2016). Pengelolaan Zakat Di Badan Amil Zakat Nasional Kabupaten Tulungagung Dalam Perspektif Maqashid Al-Syariah. Ahkam: Jurnal Hukum Islam, 4(2), 247-288.

Al Arif, M., \& Rianto, N. (2013). Fungsionalisasi Zakat dan Pajak di Dalam Perekonomian. Jurnal Ekonomi Islam, 3(1), 35-62.

Anwar, A. N., Aji, A. M., \& Tanjung, H. (2019). Analisis Kebijakan Alokasi Dana Hak Amil Menurut Prespektif Syariah Dan Implementasinya Di Organisasi Pengelola Zakat. Kasaba: Jurnal Ekonomi Islam, 10(2), 131-150.

Atabik, A. (2016). Manajemen pengelolaan zakat yang Efektif di Era Kontemporer. ZISWAF: Jurnal Zakat dan Wakaf, 2(1), 40-62.

Burhan Bungin. (2003). Analisis Data Penelitian Kualitatif. Jakarta: RajaGrafindo Persada.

Didin Hafidhuddin. (2011). Peran Strategis Organisasi Zakat Dalam Menguatkan Zakat Di Dunia. Jurnal Al-Infaq, 2(1), 1-4.

Didin Hafiduddin. (2008). Zakat dalam Perekonomian Modern (VI). Jakarta: Gema Insani Press.

Fakhruddin ar-Razi. (1981). Tafsir al-Kabir wa Mafatihu al-Ghayb (Tafsir ar-Razi) (I). Lebanon: Darul Fikr.

Firmansah, Y. (2015). Proses Penentuan Penerima Zakat, Infaq, dan Shadaqah pada Lembaga Amil Zakat di Surabaya. Al Tijarah, 1(2), 134-156.

Hafidhuddin, D. (2002). Zakat dalam perekonomian modern. Gema Insani Press.Haji Abdul Malik Karim Amrullah (HAMKA). (1993). Tafsir al-Azhar. Singapura: Pustaka Nasional Pte, Ltd.

Hakim, R. (2017). Studi Implementatif Nilai Amanah Dalam Pengelolaan Zakat Di Kota Malang: Sebuah Ikhitiar Menuju Pengelolaan Zakat Berkemajuan. In Seminar Nasional dan Gelar Produk (SENASPRO) (pp. 1033-1040). Malang: Direktorat Penelitian dan Pengabdian (DPPM), Universitas Muhammadiyah Malang. Retrieved from researchreport.umm.ac.id/index.php/research-report/article/download/1327/1545 
Hakim, R. (2020). Manajemen zakat: histori, konsepsi, dan implementasi. Jakarta: Kencana.

Hakim, R. (2017, May). Melacak Nilai-Nilai Budaya Organisasi Islami pada Organisasi Pengelola Zakat (OPS): Telaah Literatur Klasik. In Proceedings of Annual Conference for Muslim Scholars (No. Seri 1, pp. 48-55).

Hakim, R. (2018, April). Kotekstualisasi Fikih Golongan Penerima Zakat (Asnaf Tsamaniyah) Zakat Dan Relevansinya Dengan Penanggulangan Kemiskinan di Indonesian. In Proceedings of Annual Conference for Muslim Scholars (No. Series 1, pp. 393-406).

Hanif, L. (2018). Siapakah Amil Zakat? (Vol. 57). Lentera Islam.

Huda, N., Sawarjuwono, T., Yarsi, U., Putih, C., \& Airlangga, U. (2013). Akuntabilitas pengelolaan zakat melalui pendekatan modifikasi. Jurnal Akuntansi Multiparadigma, 4(3), 376-388.

Ibnu Jarir at-Thabari. (2001). Tafsir Jami'u al-Bayan 'an Ta'wil al-Qur'an (Tafsir atThabari) (I). Giza: : Haju li at-Tab'ah wa an-Nasyr wa at-Tauzi' wa al-I'lan.

Ibnu Katsir. (2000). Tafsir al-Qur'an al-'Adzim (I). Alyaban: Mu'assasah Qurtubah \& Maktabah al-Aulad as-Syaikh li at-Turast.

Ibnu Rusyd al-Andalusi. (n.d.). Bidayatu al-Mujathid wa Nihayatu al-Muqtashid. Semarang: Kereta Putra Maktabah wa Matba'ah.

Imam Nawawi al-Bantani. (2004). Sullamu at-Taufiq. (Trans. Moch. Anwar \& Anwar Abubakar, Ed.) (II). Bandung: Sinar Baru Algensindo.

J. Raco. (2003). Metode Penelitian Kualitatif: Jenis, Karakteristik, dan Keunggulannya. Jakarta: PT Grasindo.

Jalaluddin al-Mahalli \& Jalaluddin as-Suyuthi. (n.d.). Tafsir al-Qur'an al-Karim. Dar Ibnu Katsir.

Kasri, R. A. (2016). Maqasid al-Shariah and Performance of Zakah Institutions. Kyoto Bulletin of Islamic Area Studies, 9(3), 19-41.

M. Quraish Shihab. (2002). Tafsir al-Misbah: Pesan, Kesan dan Keserasian al-Qur'an. Jakarta: Lentera Hati, 2002.

Masdar Farid Mas'udi. (2010). Pajak itu Zakat (I). Bandung: Mizan.

Mohammad Nazir. (1998). Metode Penelitian (III). Jakarta: Ghalia Indonesia.

Muhammad Tahir Ibn 'Asyur. (1984). Tafsir at-Tahrir wa at-Tanwir. Tunis: Dar at-Tunis li an-Nasyr.

Nasrudin, M. (2017). Keberterimaan Amil Zakat LAZIS NU dan LAZIS Muhammadiyah terhadap Hegemoni Negara dalam Pengelolaan Zakat. Nizham Journal of Islamic Studies, 5(2), 77-95.

Nopiardo, W. (2017). Urgensi Berzakat Melalui Amil Dalam Pandangan Ilmu Ekonomi Islam. JURIS (Jurnal Ilmiah Syariah), 15(1), 85-100.

Owoyemi, M. Y., \& Cusairi, R. (2016). Zakah Administration and its Importance: A Review. IOSR Journal Of Humanities And Social Science (IOSR-JHSS), 21(6), 115120. https://doi.org/10.9790/0837-210608115120

Possumah, B. T. (2016). Had Kifayah Zakah and Adequacy of Income Redistribution: A 
Proposal Framework. International Journal of Zakat, 1(1), 36-49.

Rahayu, N. W. I. (2015). Lembaga Amil Zakat, Politik Lokal, dan Good Governance di Jember. KARSA: Journal of Social and Islamic Culture, 22(2), 207-223.

Ridwan, M. (2016). Analisis Implementasi Regulasi Zakat:(Kajian Di UPZ Desa Wonoketingal Karanganyar Demak). YUDISIA: Jurnal Pemikiran Hukum dan Hukum Islam, 7(2), 470-497.

Rosadi, A. (2017). Amil Zakat Menurut Hukum Islam dan Peraturan Perundang-Undangan. Al-Manahij: Jurnal Kajian Hukum Islam, 11(2), 189-198.

Rumaningsih, E. (2016). Prospek Integrasi Zakat dengan Pajak. Economica: Jurnal Ekonomi Islam, 1(2), 15-26.

Sayyid Quthb. (2003). Tafsir fi Dzilalil Qur'an. ( et. a. Transj. As'ad Yasin, Ed.). Jakarta: Gema Insani Press: 2003), 370.

Setiadi, M. R., \& Hambali, Y. (2016). Peran Amil Zakat Dalam Mengoptimalkan Zakat Produktif: Studi Analisis Badan Amil Zakat Daerah (BAZDA) Kota Bekasi. MASLAHAH (Jurnal Hukum Islam dan Perbankan Syariah), 7(1), 49-70.

Siregar, S. (2015). Problematika Fundrising Zakat (Studi Kasus Baznas Se-Sumatera Utara).

Susilowati, D., \& Setyorini, C. T. (2018). Efektivitas Tata Kelola Dana Zakat. Jurnal Akuntansi Multiparadigma, 9(2), 346-364.

Syafuri, S., \& Anggraeni, N. (2019). Tinjauan hukum islam terhadap praktik upah (ujrah) Amil zakat. MUAMALATUNA, 10(2), 122-141.

Toriquddin, M. (2015). Pengelolaan zakat produktif: Perspektif maqasid al-syari'ah Ibnu'Asyur. (Thesis, UIN Maulana Malik Ibrahim). Retrieved from http://repository.uin-malang.ac.id/1481/

Ugi Suharto. (2004). Keuangan Publik Islam Reinterpretasi Zakat dan Pajak: Studi Kitab al-Amwal Abu Ubayd. Yogyakarta: Pusat Studi Zakat STIS Yogyakarta.

Varlitya, C. R. (2017). Analisis Zakat Sebagai Pendapatan Asli Daerah Terhadap Indeks Pembangunan Manusia: Pendekatan Data Panel (Studi Kasus 12 Kabupaten/Kota Provinsi Aceh). Jurnal Ekonomi dan Kebijakan Publik Indonesia, 4(2), 192-211.

Wahbah Zuhaili. (1996). Tafsir al-Wajiz: 'Ala Hamisy al-Qur'an al-'Adzhim. , (SuriahDamaskus: Darul Fikr.

Wahyuniati, W., \& Hamid, H. (2017). Pengaruh Pendidikan Formal Dan Pelatihan Terhadap Kinerja Amil Zakat Di Kota Kendari (Studi pada Kecamatan Puwatu, Kecamatan Wawombalata dan Kecamatan Abeli di kota kendari). IQTISHODUNA, 12(1), 30-38.

Yusuf Qardhawi. (1996). Hukum Zakat. (Trans. Salman Harun et.al., Ed.) (IV). Jakarta: Pustaka Litera Nusantara.

Zahra, A., Harto, P. P., \& ASH, A. B. (2016). Pengukuran Efisiensi Organisasi Pengelola Zakat dengan Metode Data Envelopment Analysis. Jurnal Akuntansi dan Keuangan Islam, 4(1), 25-44.

Zen, J. (2017). Pemikiran Yusuf Al-Qaradhawi Tentang Urgensi Zakat (Doctoral dissertation, Universitas Islam Negeri Sultan Syarif Kasim Riau). Retrieved from http://repository.uin-suska.ac.id/24609/ 